\title{
Effects of Some Key Parameters on the Overall Performance of Gas Turbine
}

\author{
Pengfei Su ${ }^{1,2}$, Jianmin Gao', Shiquan Zhao², Xiangling Kong ${ }^{2}$, Yu Fang ${ }^{2}$ \\ ${ }^{1}$ State Key Laboratory of Mechanical Manufacturing Systems Engineering, Xi'an Jiaotong University, Xi'an, China \\ ${ }^{2}$ Dongfang Turbine Co., Ltd., Deyang, China
}

Email address:

supengfei@dongfang.com (Pengfei Su)

\section{To cite this article:}

Pengfei Su, JianminGao, ShiquanZhao, Xiangling Kong, Yu Fang. Effects of Some Key Parameters on the Overall Performance of Gas Turbine.International Journal of Energy and Power Engineering. Vol. 10, No. 2, 2021, pp. 37-49. doi: 10.11648/j.ijepe.20211002.12

Received: April 6, 2021; Accepted: April 23, 2021; Published: May 8, 2021

\begin{abstract}
A method for power plant Gas Turbine overall performance evaluation was developed based on the thermodynamic cycle. Some key parameters affecting the simple cycle efficiency and power of the GT, such as compressor pressure ratio, turbine inlet temperature, compressor efficiency, compressor exit diffuser $\mathrm{Cp}$, combustor pressure loss, turbine efficiency, OTDF, RTDF, blade metal allowable temperature and turbine exit diffuser $\mathrm{Cp}$ has been studied across a wide range of possible operating conditions. The effects on simple cycle of GT efficiency, GT specific power and turbine exit temperature of these parameters were discussed: The compressor pressure ratio should be chosen to give an optimumGT specific power, and should match turbine inlet temperature; When compressor efficiency increases $1 \%$, the GT efficiency increases about $0.3 \%$, while turbine efficiency increases $1 \%$, the GT efficiency increases about $0.6 \%$; When compressor exit diffuser Cp increases 0.1 , the GT efficiency increases about $0.1 \%$, while turbine exit diffuser $\mathrm{Cp}$ increases 0.1 , the GT efficiency increases about $0.25 \%$; RTDF is more important than OTDF for GT efficiency, When RTDF increases 0.05 , the GT efficiency decreases about $0.15 \%$, but When OTDF increases 0.05 , the GT efficiency only decreases about $0.02 \%$; When combustor pressure loss increases $1 \%$, the GT efficiency decreases about $0.2 \%$, but combustor pressure loss also effect turbine Nozzle1 cooling design; these parameters should be carefully considered in a new GT design.
\end{abstract}

Keywords: Gas Turbine, Overall Performance Prediction, Thermodynamic Cycle, Turbine

\section{Introduction}

GT is an advanced and complex power equipment. Facing economic globalization and competition in international market, the power plant GT is one of the top ten major technical equipments developed by China. At present, the growth of power demand in China is slowing down, while the energy structure is urgently needed to be adjusted. As the force of energy saving and emission reduction is increasing, most of the new power plants will use clean energy, and the GT is one of the main choices. However, there is no independent brand of power plant GT in China and the development of GT design technology is becoming more and more urgent.

The first key step in the design process of GT is to develop an accurate and effective theoretical analysis method for the overall performance. The effects of the relative parameters on the overall performance of GT can be obtained based on this method. Many researchers have worked on the evaluation of
GT performance. Ushiyamaand Hadikestablished the theoretical formulas to estimate the performance of GT under varying atmospheric conditions $[1,2]$. The thermal efficiency and the specific network of a GT were calculated and studied at different maximum turbine inlet temperature (TIT), pressure ratio, and variable environmental conditions. Baugh et al. reported an analysis to the thermodynamic performance of a GT cogeneration plant[3]. Fuel chargeable to power, fuel chargeable to incremental power and differential steam efficiency were defined to assess the effects of partial load, cooling inlet air temperature and super charging on the performance of the plant. They found that, the GT typically produces $30 \%$ higher output at $-6.6^{\circ} \mathrm{C}$ than at $35^{\circ} \mathrm{C}$. Subsequently, Khaliq and Choudharydeveloped an indirect intercooled reheat regenerative GT cycle with inlet air cooling and evaporative after cooling of the compressor discharge[4]. They provided a combined first and second-law computational analysis to investigate the effects of cycle 
pressure ratio, turbine inlet temperature, and ambient relative humidity on the thermodynamic performance of the cycle. Cai derived the expressions for efficiencies and power ratios between GT and steam turbine, various typical combined cycles such as pressurized fluidized bed type[5], fully fired type, and pure heat recovery types were studied. The effect of the optimum GT pressure ratio on efficiency of these combined cycles was discussed. Yoshida et al. developed a GT performance analysis method based on the actual measured operating conditions[6]. Sanjay et al. compared and analyzed the performance of cogeneration GT cycle for different blade cooling approaches[7, 8]. It is useful for GT designers to select the optimum compressor pressure ratio, turbine inlet temperature, fuel utilization efficiency, power-to-heat ratio, and appropriate cooling methods for a specified plant specific work and process heating requirement. Kumar and Singh reported the effect of the TIT and the compressor pressure ratio on the performance of simple aero GT cycle with transpiration cooling of turbine blades [9]. Shukla and Singh investigated the combined effect of inlet evaporative cooling, steam injection and film cooling on the performance of steam-injected GT (STIG) based power plant with inlet evaporative cooling [10]. Elwekeel and Abdala developed the energy and exergy analyses for steam injected GT cycle with a closed loop cooling technique by using steam and steam $/ \mathrm{mist}$ [11]. Their results show that the efficiency can reach $47.2 \%$ at low coolant temperature with a mist fraction of $2 \%$. Singh et al. reported the effect of various operating parameters on the performance of a dual pressure HRSG combined cycle power plant [12]. Their results reveal that the combined cycle power plant gives best performance at low ambient air temperature, high compressor pressure ratio and high turbine inlet temperature.

Literatures indicate that the performance evaluation of various GT cycles is relatively up to mature. This paper deals with a simple cycle performance analysis for a GT based on the Brayton cycle. Employing the developed method, effects of some key parameters such as compressor pressure ratio, turbine inlet temperature, compressor efficiency, compressor exit diffuser $\mathrm{Cp}$, combustor pressure loss, turbine efficiency, OTDF, RTDF, blade metal allowable temperature and turbine exit diffuser $\mathrm{Cp}$ are obtained. Through the study of GT performance prediction, this paper is expected to provide more reasonable suggestions for GT cycle parameter selections.

\section{Component Modeling and Governing Equations}

The GT simple cycle mainly includes compressors, combustion chamber, and cooled expansion turbine. The arrangement illustrated schematically in Figure 1 shows the flow diagram for the cycle. The operating principle of a GT is simplified as follows: the ambient atmospheric air enters an intake section and then is drawn into a multistage axial flow compressor. Most of the compressed air then passes through the combustion chamber where fuel is injected and burned. The products of combustion enter the turbine and expand to approximately atmospheric pressure through the exhaust section. Some of the compressed air is used as the coolant to cool the high temperature vanes and blades of turbine stage. Almost half of the turbine power is used to drive the compressor, while the remainder is delivered to the equipment external of the GT.

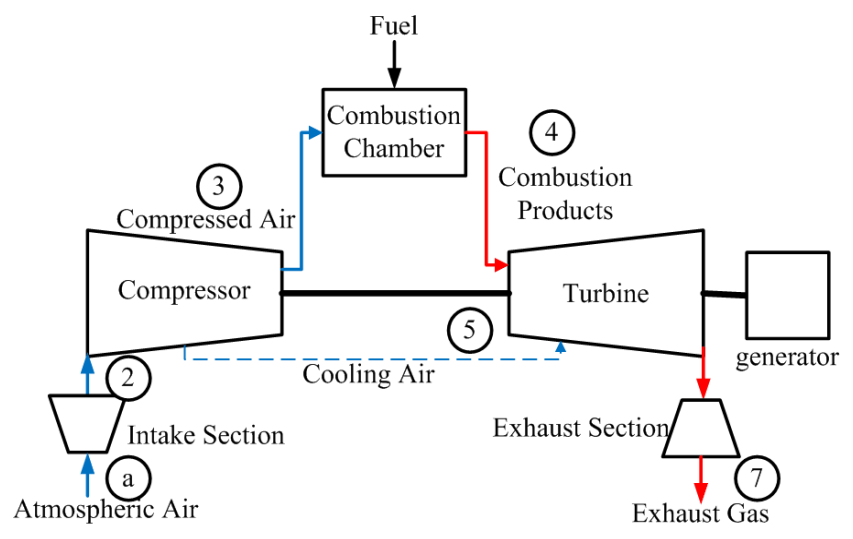

Figure 1. Simple GT arrangement.

\section{Intake Section and Compressor}

\subsection{Intake Section and Compressor}

The thermodynamic state points of the ideal and actual processes in the intake section and the compressor are illustrated in figure 2 .

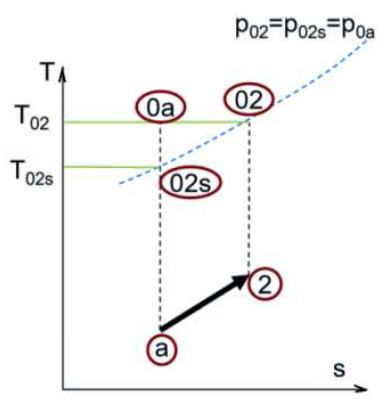

(a) intake section

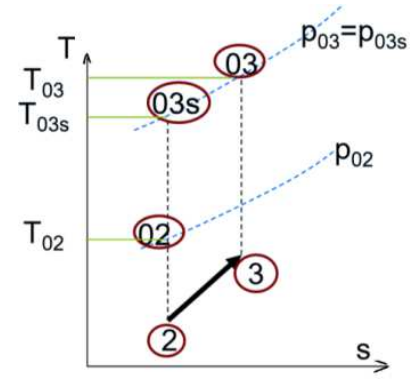

(b) compressor

Figure 2. T-S diagrams for the processes in the intake section and the compressor:

The changes in the processes of the intake section are 
expressed by the formulations as follows.

$$
\begin{gathered}
P_{02}=P_{02 s}=\left(\frac{P_{02 s}}{P_{0 a}}\right) \cdot p_{0 a}=\left(\frac{T_{02 s}}{T_{0 a}}\right)^{\gamma /(\gamma-1)} \cdot P_{a}\left(1+\frac{\gamma-1}{2} M_{a}^{2}\right)^{\gamma /(\gamma-1)} \\
\frac{P_{0 a}}{P_{a}}=\left(1+\frac{\gamma-1}{2} M_{a}^{2}\right)^{\gamma /(\gamma-1)} \\
\frac{T_{0 a}}{T_{a}}=1+\frac{\gamma-1}{2} M_{a}^{2} \\
\frac{P_{02 s}}{P_{0 a}}=\left(\frac{T_{02 s}}{T_{0 a}}\right)^{\gamma /(\gamma-1)} \\
P_{02}=P_{a}\left(1+\frac{T_{02 s}+T_{a}}{T_{02}-T_{a}} \cdot \frac{T_{02}-T_{a}}{T_{a}}\right)^{\gamma /(\gamma-1)}=P_{a}\left(1+\eta_{\text {int } a k e} \cdot \frac{T_{02}-T_{a}}{T_{a}}\right)^{\gamma /(\gamma-1)}
\end{gathered}
$$

Where $P, T, \gamma, M a$ are the pressure, temperature, isentropic exponent, Mach number, respectively. AndI/intake is the adiabatic intake efficiency. The subscripts of "a" and "2" represent the entrance of the intake section and the compressor respectively as showed in Figure 1, while the subscript of "s"

represents the isoentropic process in the ideal state.

The changes in the processes of the compressor are expressed by the formulations as follows.

$$
P_{03}=P R \cdot P_{02}
$$

$$
\begin{aligned}
& T_{03}=T_{02}\left(1+\left(\frac{T_{03}-T_{02}}{T_{02}}\right)\right)=T_{02}\left(1+\left(\frac{T_{03}-T_{02}}{T_{03}-T_{02}}\right) \cdot\left(\frac{T_{03 s}}{T_{02}}-1\right)\right) \\
& =T_{02}\left(1+\frac{1}{\eta_{e}} \cdot\left(\left(\frac{P_{03}}{P_{02}}\right)^{(\gamma-1) / \gamma}-1\right)\right)=T_{02}\left(1+\frac{1}{\eta_{e}} \cdot\left(P R^{(\gamma-1) / \gamma}-1\right)\right)
\end{aligned}
$$

Where $P R$ is the compressor pressure ratio and $\eta_{c}$ is the adiabatic compressor efficiency. The subscript of "3" represents the exit of the compressor as shows in Figure 2(b).

\subsection{Combustion Chamber}

For the combustor, $T_{04}$ is given based on the maximum allowable turbine inlet temperature. Applying the energy equation across the combustor, the changes in the process are expressed by the formulations as follows.

$$
\begin{gathered}
\int_{A} \rho h_{0} V \cdot d A=m_{f} Q \\
h_{04} \cdot\left(m_{i}+m_{f}\right)-h_{03} \cdot m_{i}=m_{f} \cdot Q \\
h_{04} \cdot(1+F A R)-h_{03}=F A R \cdot Q \\
F A R=\frac{h_{03}-h_{04}}{h_{04}-Q}=\frac{h_{04} / h_{03}-1}{Q / h_{03}-h_{04} / h_{03}}
\end{gathered}
$$

Where $m_{f}, m_{i}$ are the mass flow of the fuel and the entering air from the compressor respectively. FAR is the fuel-air ratio. It is assumed that specific heat of the fuel-air mixture in the combustor can be given of $\mathrm{Cp}$, with the correlation of $\mathrm{Cp}$ from P.P.Walsh\& P Fletcher [13].

$$
F A R=\frac{h_{04} / h_{03}-1}{Q / C_{p} T_{03}-h_{04} / h_{03}}
$$

Since the burning flow in the combustor is generally the Rayleigh flow, then frictional losses in combustion may also contribute to the pressure loss. In the Rayleigh flow:

$$
\frac{P_{04}}{P_{03}}=\frac{1+\gamma M_{a 3}^{2}}{1+\gamma M_{a 4}^{2}} \cdot\left(\frac{1+\frac{\gamma-1}{2} M_{a 4}^{2}}{1+\frac{\gamma-1}{2} M_{a 3}^{2}}\right)^{\gamma /(\gamma-1)}
$$

\subsection{Turbine and Exhaust Section}

The thermodynamic state points of the ideal and actual processes in turbine and the exhaust section are illustrated in Figure 3. In a fashion closely analogous to the definition for the compressor, an empirical correlation is used for the prediction of the cooling air based on the nozzle and rotor blade inlet temperature and the blade allowable metal temperature (see Appendix). The changes in the process of GT are expressed by the formulations as follows. 


$$
\begin{gathered}
\frac{P_{04}}{P_{05}}=\left(1-\frac{1}{\eta_{t}}\left(1-\frac{T_{04}}{T_{05}}\right)\right)^{\gamma /(\gamma-1)} \\
T_{05}=T_{04}-\left(T_{03}-T_{02}\right)
\end{gathered}
$$

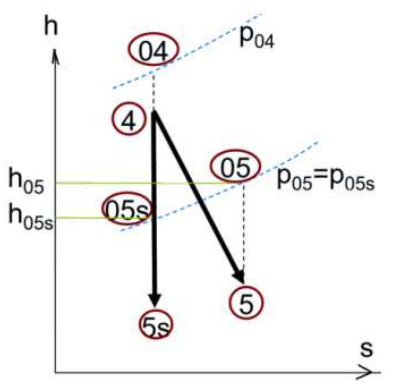

(a) turbine

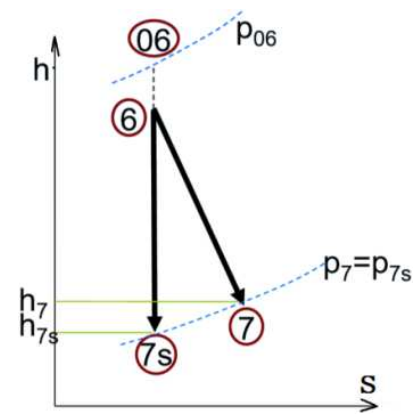

(b) exhaust section

Figure 3.H-S diagrams for the processes in gas turbine and the exhaust section.

Without afterburner, $P_{06}=P_{05}, T_{06}=T_{05}$, the parameters are changed in the exhaust section as follows.

$$
h_{07}=h_{7}+\frac{u_{7}^{2}}{2}
$$

Since the enthalpy values of $h_{06}$ and $h_{07}$ are equal, then

$$
\begin{gathered}
h_{06}-h_{7}=\frac{u_{7}^{2}}{2} \\
\frac{h_{06}-h_{7}}{h_{06}-h_{7 s}}=\eta_{n}, \eta_{n} \cdot\left(h_{06}-h_{7 s}\right)=\frac{u_{7}^{2}}{2} \\
C_{p}=\frac{\gamma R}{\gamma-1}, u_{7}^{2}=2 \eta_{n} \cdot \frac{\gamma R}{\gamma-1}\left(T_{06}-T_{7 s}\right)
\end{gathered}
$$

Since the equations of $\frac{T_{7 s}}{T_{05}}=\left(\frac{P_{7 s}}{P_{05}}\right)^{(\gamma-1) / \gamma}$ and $P_{a}=P_{7}=P_{7 s}$ hold, then

$$
u_{e}=\sqrt{2 \eta_{n} \cdot \frac{\gamma R}{\gamma-1} T_{05}\left(1-\left(\frac{P_{a}}{P_{05}}\right)^{(\gamma-1) / \gamma}\right)}
$$

where $u_{e}$ is the exit speed of the exhaust section.

So far, the expressions for $F A R$ and $u_{e}$ can be given by mission requirements, attainable compressor pressure ratio, turbine inlet temperature, fuel, component efficiencies and some other assumptions. Once FAR and $u_{e}$ are computed, the overall performance of GT can be determined.

\section{Validation}

The predictive ability of the method has been assessed by modelling 2 GTs, from two manufacturers, one is L20A and the other is M701F3 [14, 15], where sufficient data are known, or can be reasonably derived, from the open literature. The predicted engine parameters have then been tuned to give a good match to published engine actual performance data. Table 1 records the significant results.

Table 1. Matches to GTs.

\begin{tabular}{lllll}
\hline GT & L20A & Prediction & M701F3 & Prediction \\
\hline Mass flow $(\mathrm{kg} / \mathrm{s})$ & 57 & 57 & 651 & 651 \\
TIT $\left({ }^{\circ} \mathrm{C}\right)$ & 1250 & 1250 & 1400 & 1700 \\
PR & 18 & 18 & 585 & 17 \\
Exhaust gas temperature $\left({ }^{\circ} \mathrm{C}\right)$ & 545 & 543.4 & 38.2 & 582.4 \\
Thermal Efficiency $(\%)$ & 35 & $34.95 \%$ & 270.3 & 38.11 \\
Power $(\mathrm{MW})$ & 18 & 18.48 & & 270.69 \\
Coolant Fraction(\%) & & $14.6 \%$ & $17.87 \%$ \\
Compressor inlet dp/p & & 0.005 & 0.005 \\
Combustor dp/p & & 0.045 & 0.045 \\
Compressor exit diffuser Cp & & 0.55 & 0.55 \\
Compressor exit M & & 0.26 & 0.26 \\
Turbine exit diffuser Cp & 0.6 & & 0.6 \\
Mechanical efficiency & $99 \%$ & & $99 \%$ \\
Gearbox efficiency & $96 \%$ & & $96 \%$ \\
Alternator efficiency & $98.5 \%$ & & $98.5 \%$ \\
Combustor efficiency & $99 \%$ & & $99 \%$ \\
Fuel LCV $(\mathrm{kJ} / \mathrm{kg})$ & & 47889 & & 47889 \\
Maximum nozzle Metal T $\left({ }^{\circ} \mathrm{C}\right)$ & 870 & & 900 \\
\hline
\end{tabular}




\begin{tabular}{|c|c|c|c|c|}
\hline GT & L20A & Prediction & M701F3 & Prediction \\
\hline Maximum rotor Metal $\mathrm{T}\left({ }^{\circ} \mathrm{C}\right)$ & & 870 & & 900 \\
\hline $1^{\text {st }}$ stage OTDF & & 0.2 & & 0.2 \\
\hline Nozzle peak $T$ reduction factor & & $20 \%$ & & $20 \%$ \\
\hline $1^{\text {st }}$ stage OTDF & & 0.05 & & 0.05 \\
\hline Rotor peak $\mathrm{T}$ reduction factor & & $50 \%$ & & $50 \%$ \\
\hline
\end{tabular}

\section{Research on the Sensitivity of Design Parameters}

The sensitivity of the technical parameters variation like compressor pressure ratio, turbine inlet temperature, compressor efficiency, compressor exit diffuser $\mathrm{Cp}$, combustor pressure loss, turbine efficiency, OTDF, RTDF, blade metal allowable temperature and turbine exit diffuser $\mathrm{Cp}$ has been studied, to optimize the overall performance of the GT, and guarantee the choice of the parameters in a reasonable range.

\subsection{Compressor Pressure Ratio}

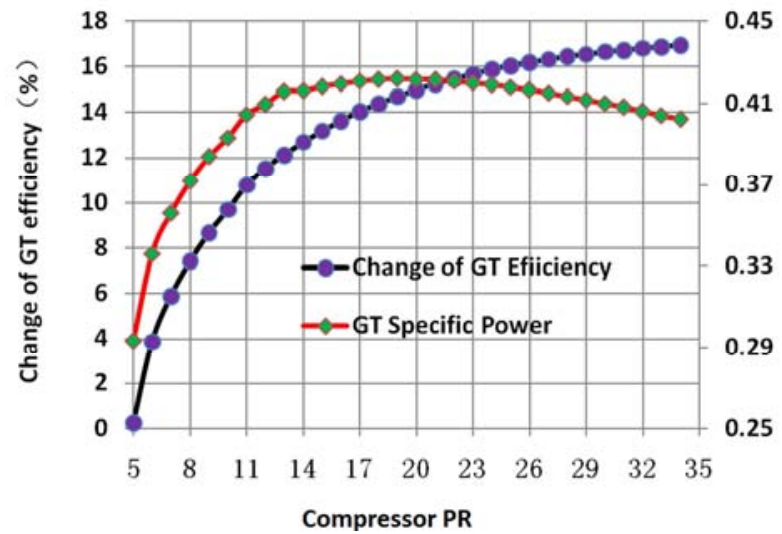

(a)

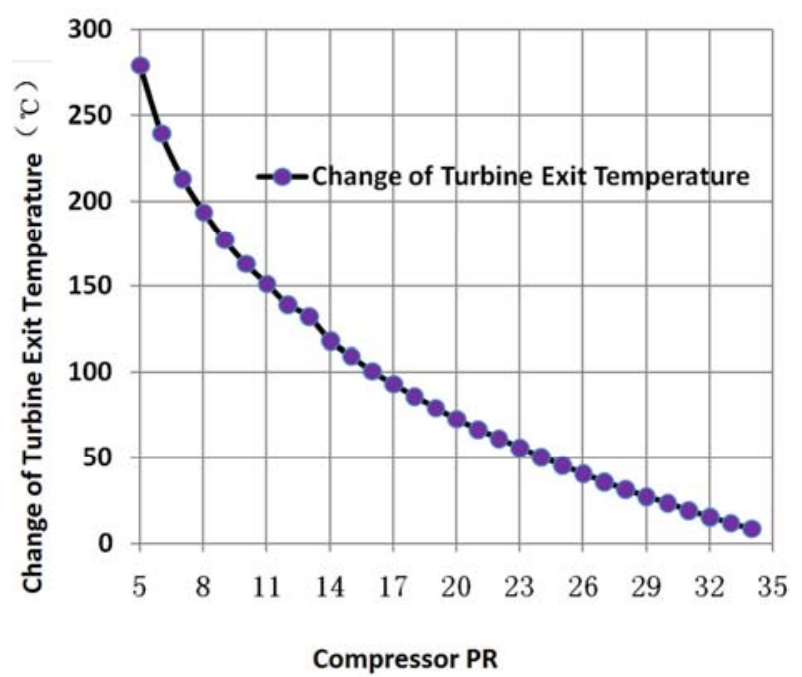

(b)

Figure 4.Effect of Compressor Pressure Ratio.

The resulting trends of GT efficiency, GT specific power and turbine exit temperature with the variation of compressor pressure ratio are presented in Figure 4. Because this study is for the industry GT, the compressor pressure ratio for this kind of GT is usually below 35 , so the pressure ratio of 5 to 35 is used in this study.

It can be seen that the higher the compressor pressure ratio, the higher the efficiency of the GT, when the compressor pressure ratio increases from 5 to 35 , the GT efficiency increases by $16.7 \%$, and a formula is used to show the relationship between GT efficiency and compressor pressure ratio:

$$
y=6 E-06 x^{5}-0.000 x^{4}+0.031 x^{3}-0.688 x^{2}+7.894 x-25.08(21)
$$

$\mathrm{y}$ stands for GT efficiency and $\mathrm{x}$ stands for compressor pressure ratio.

The trend of GT specific power is different, it has an optimum pressure ratio between 18 to 19 at the given assumptions, when the compressor pressure ratio below this optimum number, the GT specific power increases from 0.29 $\mathrm{MW} / \mathrm{kg} / \mathrm{s}$ to $0.42 \mathrm{MW} / \mathrm{kg} / \mathrm{s}$ when the compressor pressure ratio inreases from 5 to 18 , and decreases from $0.42 \mathrm{MW} / \mathrm{kg} / \mathrm{s}$ to $0.4 \mathrm{MW} / \mathrm{kg} / \mathrm{s}$ when the compressor pressure ratio inreases from 18 to 35 . The optimum pressure ratio for the GT specific power will increase with the increasing of turbine inlet temperature, and the optimum pressure ratio for simple cycle specific power is consistent with the optimum pressure ratio for combined cycle in most cases. A formula is used to give the relationship between GT specific power and compressor pressure ratio:

$$
y=7 E-08 x^{5}-8 E-06 x^{4}+0.000 x^{3}-0.008 x^{2}+0.094 x-0.004
$$

y stands for GT specific power and x stands for GT specific power.

Figure 4(b) gives that turbine exit temperature decreases with the increasing of compressor ratio, when the compressor pressure ratio increases from 5 to 35 , turbine exit temperature i decreases by $270^{\circ} \mathrm{C}$. Turbine exit temperature must be carefully considered for it's affecting of turbine exit diffuser materal selection and the efficiency of steam turbine.

Most of the GT companies are committed to improving the compressor pressure ratio to increase the efficiency of the GT, as the Figure 5 shows in the below. However, this is only for the simple cycle efficiency of GT. For the combined cycle, the efficiency does not always increase with the compressor pressure ratio, while there is an optimum pressure ratio, and this optimum pressure ratio is consistent with the optimum pressure ratio for GT specific power in most cases, however this will not be discussed in this paper. 


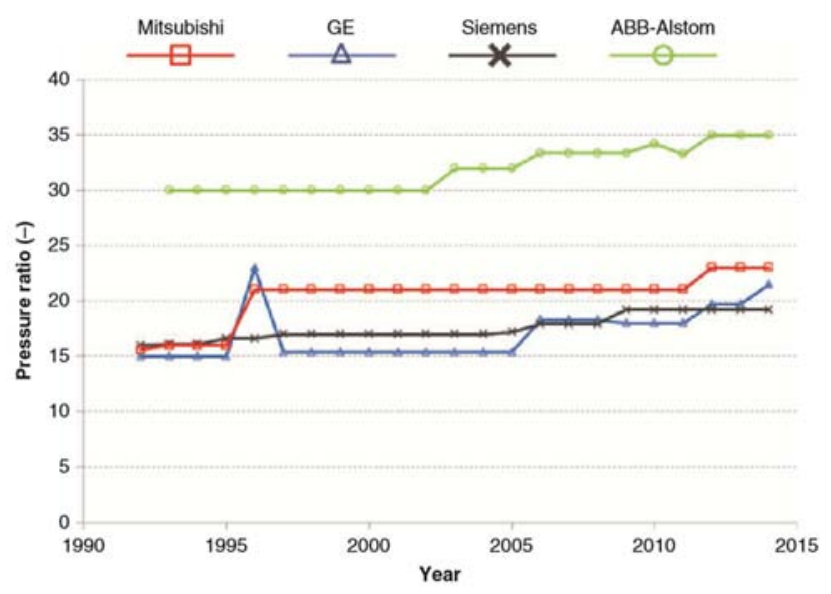

Figure 5.The Trend of Pressure Ratio of Main Gas Turbine Companies[16].

\subsection{Compressor Efficiency}

The change of compressor efficiency varies in the range of $0-12 \%$ in this study. The resulting trends of GT efficiency, GT specific power and turbine exit temperature with the variation of compressor efficiency are presented in Figure 6. Figure 6(a) shows that both GT efficiency and GT specific power nearly have a linear increase with the increasing of compressor efficiency. When compressor efficiency increases $1 \%$, the GT efficiency increases about $0.3 \%$, while the GT specific power increases about 0.01 $\mathrm{MW} / \mathrm{kg} / \mathrm{s}$. Figure 6(b) shows turbine exit temperature is nearly kept the same when the compressor efficiency varies.

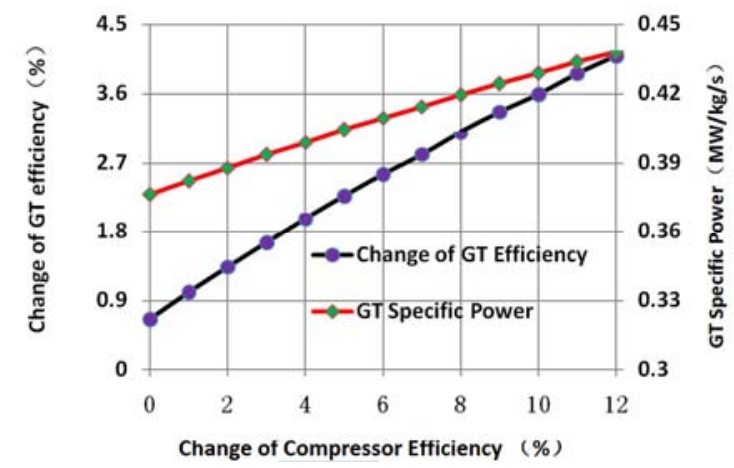

(a)

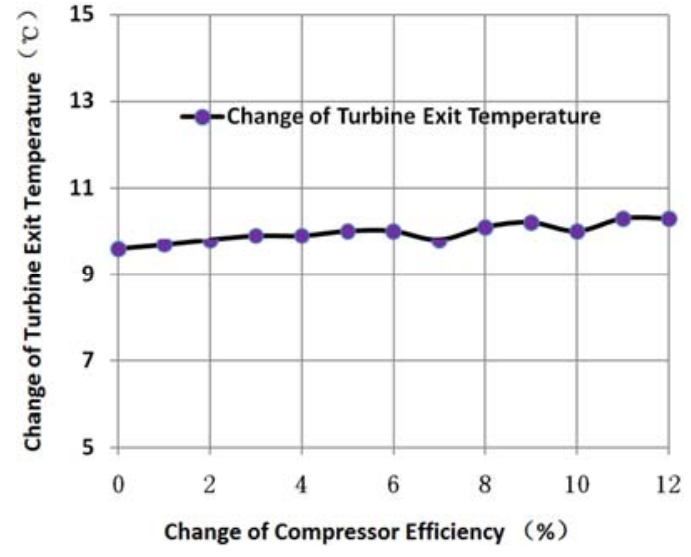

(b)

Figure 6. Effect of Compressor Efficiency.

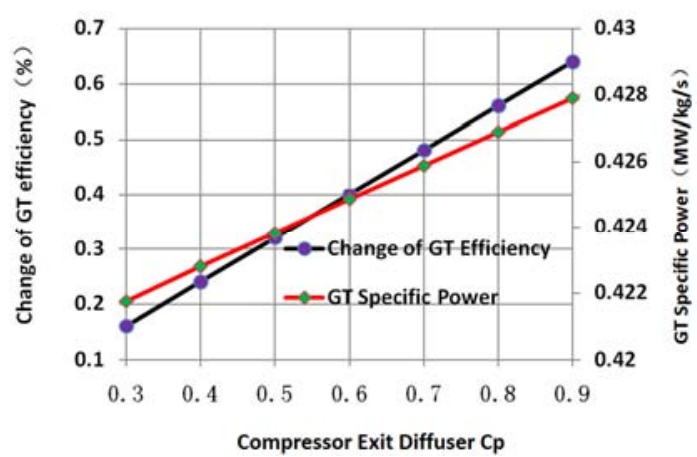

(a)

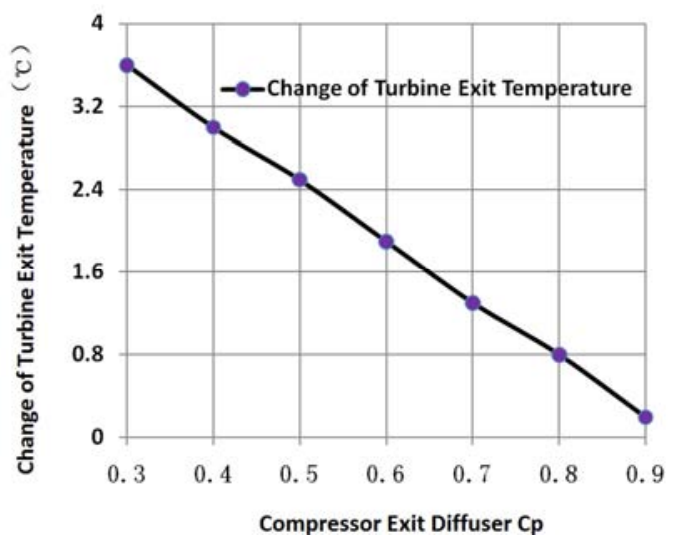

(b)

Figure 7. Effect of Compressor Exit Diffuser Cp.

\subsection{Compressor Exit Diffuser $C p$}

Compressor exit diffuser $\mathrm{Cp}$ varies from 0.3 to 0.9 in the calculation. The resulting trends of GT efficiency, GT specific power and turbine exit temperature with the variation of compressor exit diffuser $\mathrm{Cp}$ are presented in Figure 7. Figure 7(a) shows that both GT efficiency and GT specific power nearly have a linear increase with the increasing of $\mathrm{Cp}$. When compressor exit diffuser $\mathrm{Cp}$ increases 0.1 , the GT efficiency increases about $0.1 \%$, while the GT specific power increases about $0.001 \mathrm{MW} / \mathrm{kg} / \mathrm{s}$. Figure 7(b) shows turbine exit temperature has a linear decrease with the increasing of $\mathrm{Cp}$, when compressor exit diffuser $\mathrm{Cp}$ increases 0.1 , turbine exit temperature decreases about $0.6^{\circ} \mathrm{C}$.

\subsection{Combustor Pressure Loss}

Combustor pressure loss varies in the range of $1 \%-7 \%$ in this study. The resulting trends of GT efficiency, GT specific power and turbine exit temperature with the variation of combustor pressure loss are presented in Figure 8. Figure 8(a) shows that both GT efficiency and GT specific power nearly have a linear decrease with the increasing of combustor pressure loss. When combustor pressure loss increases $1 \%$, the GT efficiency decreases about $0.2 \%$, while the GT specific power decreases about $0.002 \mathrm{MW} / \mathrm{kg} / \mathrm{s}$. Figure 8(b) shows turbine exit temperature has a linear increase with the increasing of combustor pressure loss, when the loss increases $1 \%$, turbine exit temperature increases about $1.3^{\circ} \mathrm{C}$. 


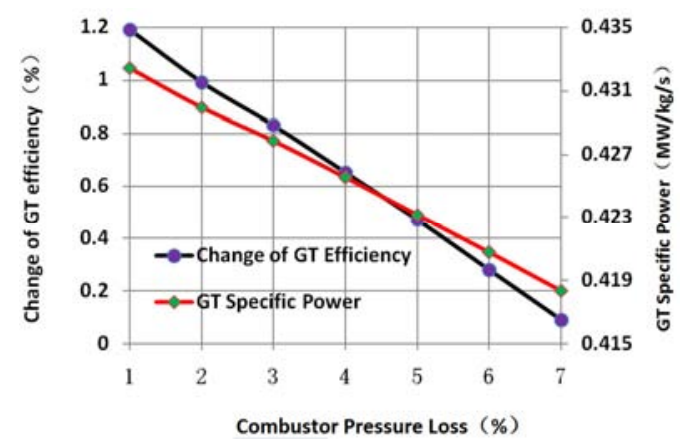

(a)

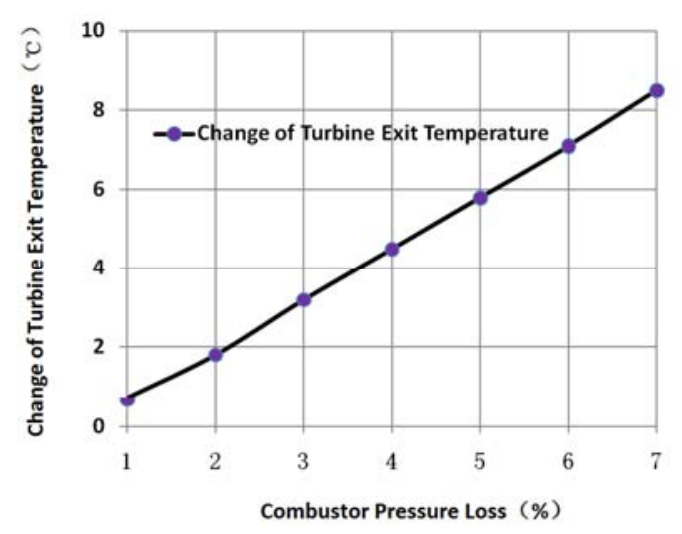

(b)

Figure 8. Effect of Combustor Pressure Loss.

\subsection{Turbine Inlet Temperature}

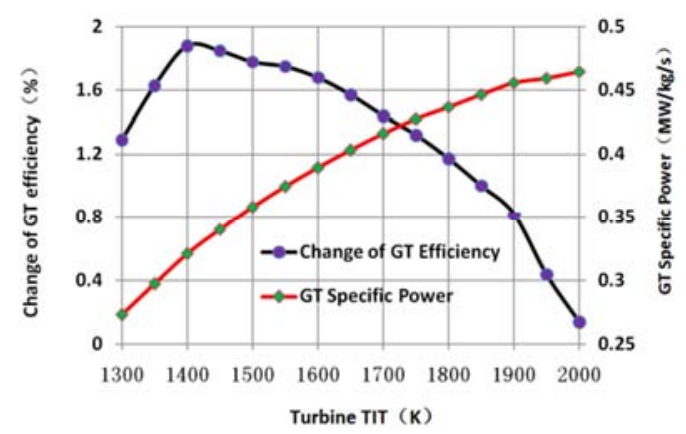

(a)

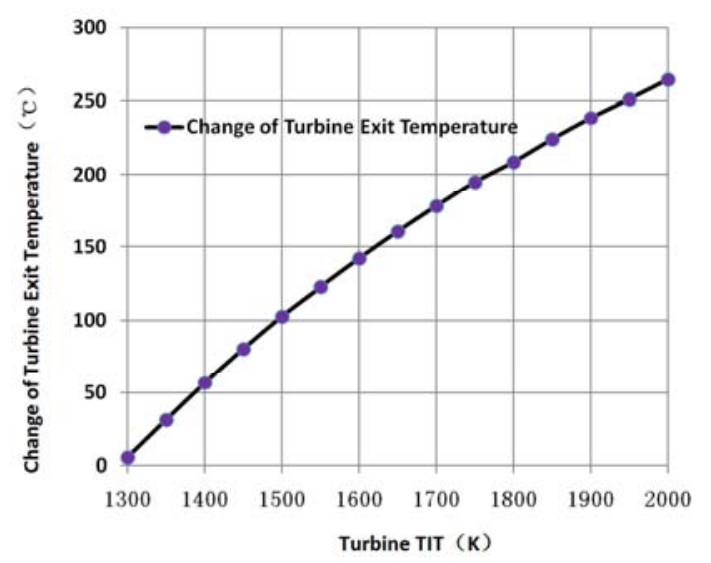

(b)

Figure 9. The effect of Turbine inlet Temperature.
Turbine inlet temperature varies from $1300 \mathrm{k}$ to $2000 \mathrm{~K}$ in the calculation for the given assumptions and technology level (turbine cooling and materials), which is the possible range for industry GT. The resulting trends of GT efficiency, GT specific power and turbine exit temperature with the variation of turbine inlet temperature are presented in Figure 9.

Figure 9(a) shows that when the turbine inlet temperature increases from $1300 \mathrm{~K}$ to $2000 \mathrm{~K}$, the GT efficiency has a significant increasing till $1400 \mathrm{~K}$, then GT efficiency decreases, GT has a best efficiency when the turbine inlet temperature is $1400 \mathrm{~K}$ in this calculation; GT specific power inceases with the inceasing of turbine inlet temperature, GT specific power increases from $0.27 \mathrm{MW} / \mathrm{kg} / \mathrm{s}$ to $0.47 \mathrm{MW} / \mathrm{kg} / \mathrm{s}$ when the turbine inlet temperature inreases from $1300 \mathrm{~K}$ to $2000 \mathrm{~K}$.

Figure 9(b) shows that turbine exit temperature is increased with the increasing of turbine inlet temperature. Turbine exit temperature increases $259^{\circ} \mathrm{C}$ when the turbine inlet temperature increases from $1300 \mathrm{~K}$ to $2000 \mathrm{~K}$.

For this calculation conditons, the cooling air flow will increase when the turbine inlet temperature increases, so the GT efficiency decreases when the turbine inlet temperature is above $1400 \mathrm{~K}$, the GT specific power and turbine exit temperature have a significant increasing with increased fuel.

It is different for the real GT design, when the inlet temperature increases, the turbine blade will use better material, lower thermal conductivity TBC coating and advanced cooling technology to reduce cooling air flow. And most GT companies are generally using advanced blade cooling technology to reduce the amount of cooling air for higher GT efficiency and Power. Figure 10 shows the variety of turbine blade materials, coating and cooling technology of the GT development in Mitsubishi. It can be found that the material used in the high temperature turbine blade has been continuously improved. The equiax crystal (EC) material were used in D class and F class GT tubine blades, the material for F class GT tubine blades has longer creep life at evevated temperature, and the low-cycle and the high-cycle fatigue life performance is better than the D class materal, with better high temperature strength, improved oxidation resistance and hot corrosion performance. The diectionally solidified (DS) material is used in G class GT, and single crystal (SC) material is used in 1700 degrees GT to improve the temperature margin of 100 degrees compared to the DS material. Some simple internal cooling holes are used for row 1 blade cooling in D class GT turbine. Serpentine passage with turbulated ribs and pinfins are used for row 1 blade internal cooling, while the shower head cooling and film cooling are used in F class GT turbine. For the row 1 blade cooling in G class GT turbine, Serpentine passage with angled turbulated ribs and with slot instead of pinfins are used for internal cooling, and the shower head cooling and full coverage film cooling are used to get a temperature margin of 50 degrees compared to the cooling technology used in F class GT turbine. Mitsubishi will use high performance cooling technology in the 1700 degree GT turbine blade to improve the temperature margin of another 50 degree compared to the cooling technology used in G class GT turbine. There are no thermal barrier coatings for the D-class 
GT turbine blade and F-class GT turbine blade for the initial designs, but the thermal barrier coatings are used for the modified D-class and M701F3 GT turbine blades, and the application of thermal barrier coating in G-class and 1700 degrees GT can improve the temperature margin of 50 degrees for each generation.

GE uses the turbine blade cooling technology which is used in aircraft engine for the H-class GT turbine blades, these cooling technology greatly enhances the blade cooling effectiveness. The latest 9HA.02 Gas Turbine gets an efficiency of $43.9 \%$ for simple cycle, and combined cycle efficiency can go up to $63.5 \%$, which is the world's highest efficiency at the current time [18]. Hitachi uses the wet air for the cooling of nozzle 1 in its H50 GT. Figure 11 shows the nozzle cooling structure, because the heat flux of wet air is bigger than air, so it can significantly increase the blade cooling effectiveness and reduce the mass flow of cooling air, these will result in a higher GT efficiency and power. Figure 12 shows the effect of the turbine inlet temperature on the efficiency of current GTs, where sufficient data can be found from the open literature. The GT efficiency will increase when the turbine inlet temperature is increased, owning to the use of high temperature materials, high performance cooling and advanced TBC when the temperature is increased.

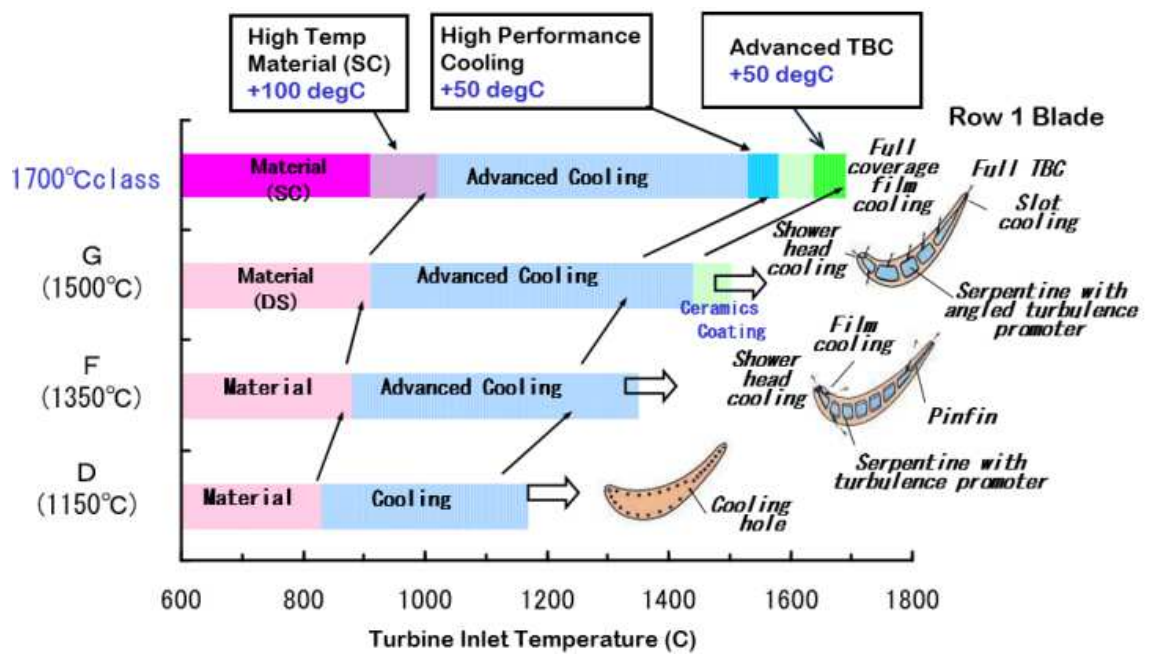

Figure 10. The development of materials, coating and cooling technology [17].

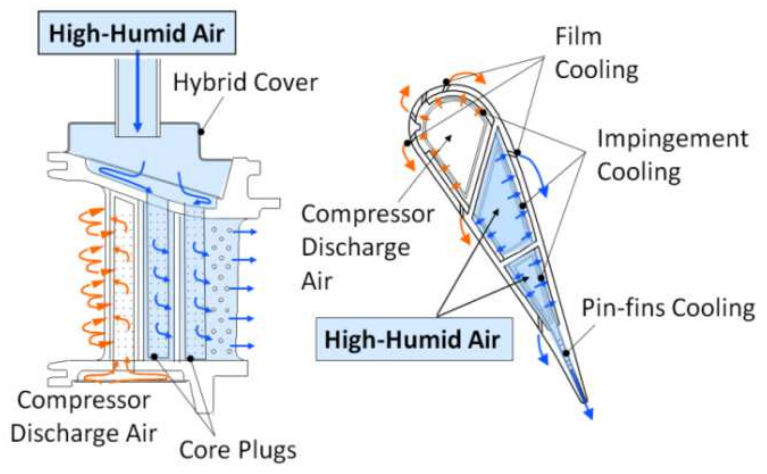

Figure 11. H50 Nozzle cooing structure[19].

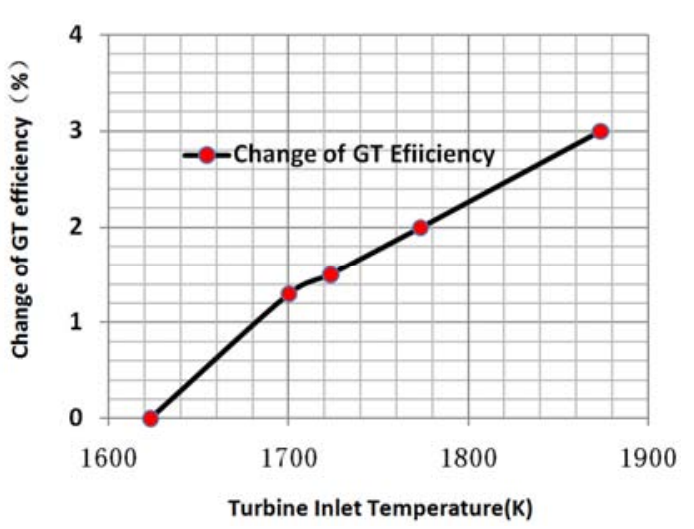

Figure 12. The effect of turbine inlet temperature of current GTs.

\subsection{OTDF\&RTDF}

OTDF and RTDF vary in the ranges of $0-0.4$ and $0-0.2$ respectively in this study, which are thought to be possible ranges for industry GT. The resulting trends of GT efficiency, GT specific power and turbine exit temperature with the variation of OTDF and RTDF are presented in Figure 13. Figure 13(a) and (c) shows that both GT efficiency and GT specific power nearly have a linear decrease with the increasing of OTDF and RTDF. When OTDF increases 0.05, the GT efficiency decreases about $0.02 \%$, while the GT specific power decreases about $0.002 \mathrm{MW} / \mathrm{kg} / \mathrm{s}$; When RTDF increases 0.05 , the GT efficiency decreases about $0.15 \%$, while the GT specific power decreases about $0.004 \mathrm{MW} / \mathrm{kg} / \mathrm{s}$. 
Figure 13(b) and (d) shows turbine exit temperature has a linear decrease with the increasing of OTDF and RTDF, when OTDF increases 0.05 , turbine exit temperature decreases about $5^{\circ} \mathrm{C}$; Turbine exit temperature decreases about $2.3^{\circ} \mathrm{C}$ while RTDF increases 0.05 .

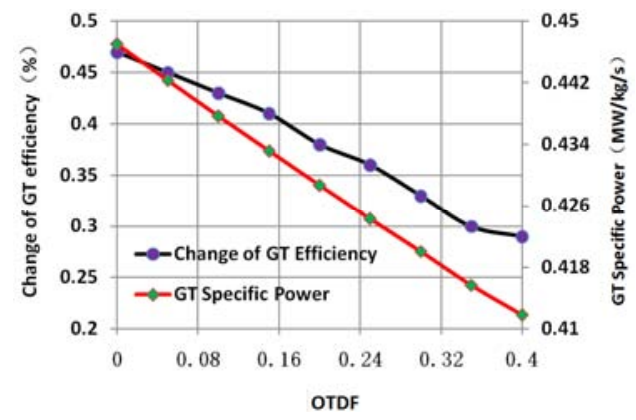

(a)

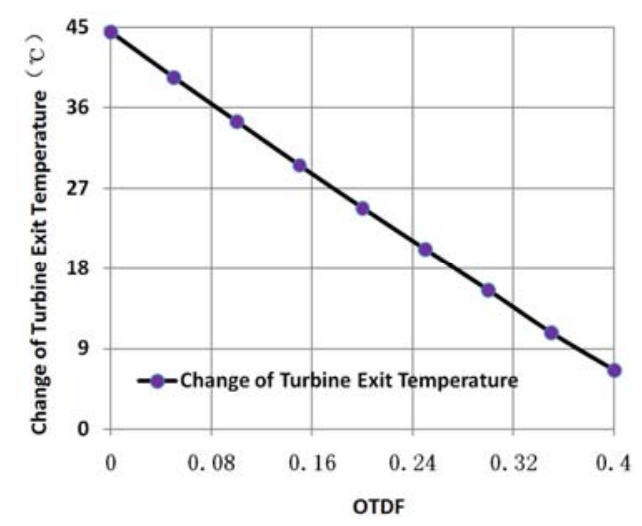

(b)

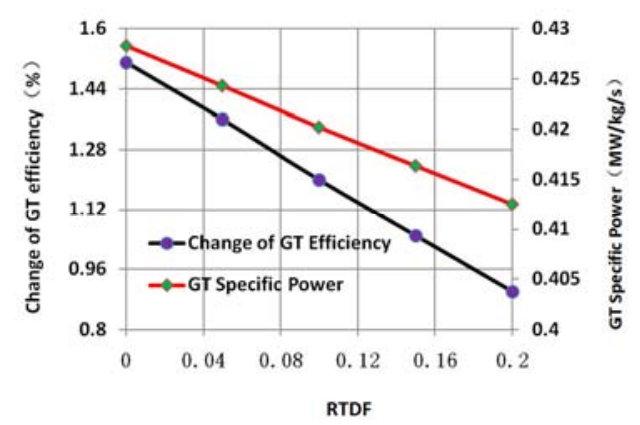

(c)

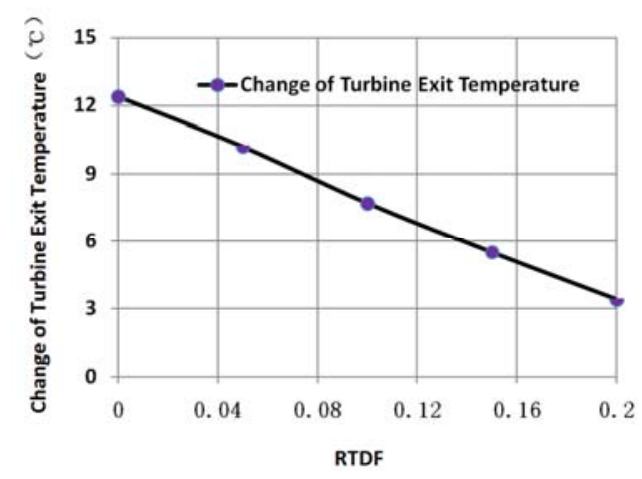

(d)

Figure 13. The effect of OTDF\&RTDF.

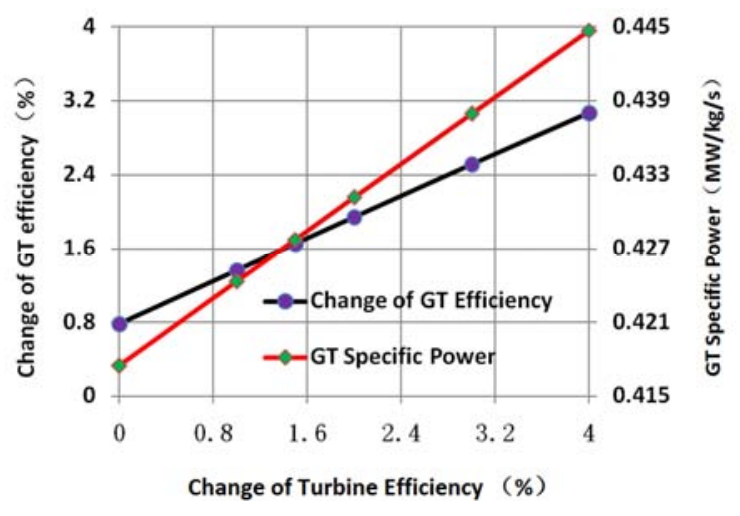

(a)

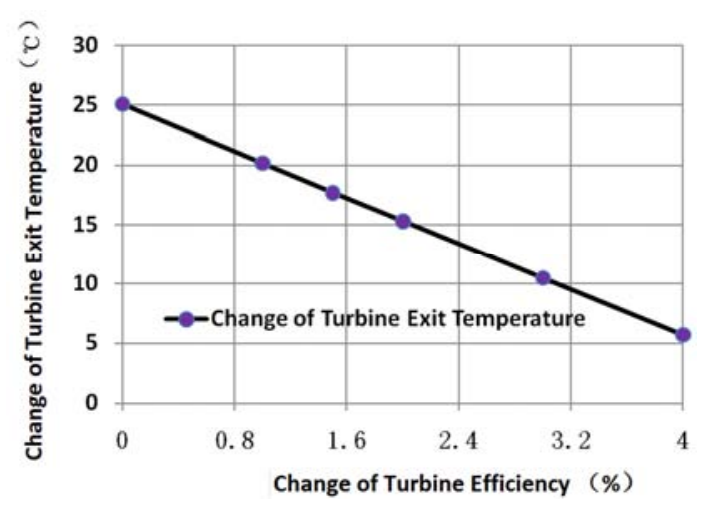

(b)

Figure 14. The effect of Turbine Efficiecy.

\subsection{Turbine Efficiency}

The change of turbine efficiency varies in the range of $0-4 \%$ in this study. The resulting trends of GT efficiency, GT specific power and turbine exit temperature with the variation of turbine efficiency are presented in Figure 14. Figure 14(a) shows that both GT efficiency and GT specific power nearly have a linear increase with the increasing of turbine efficiency. When turbine efficiency increases $1 \%$, the GT efficiency increases about $0.6 \%$, while the GT specific power increases about $0.007 \mathrm{MW} / \mathrm{kg} / \mathrm{s}$. Figure 14(b) shows turbine exit temperature nearly has a linear decrease with the increasing of turbine efficiency, turbine exit temperature decreases about $5^{\circ} \mathrm{C}$ when turbine efficiency increases $1 \%$.

\subsection{Turbine Blade Tip Clearance}

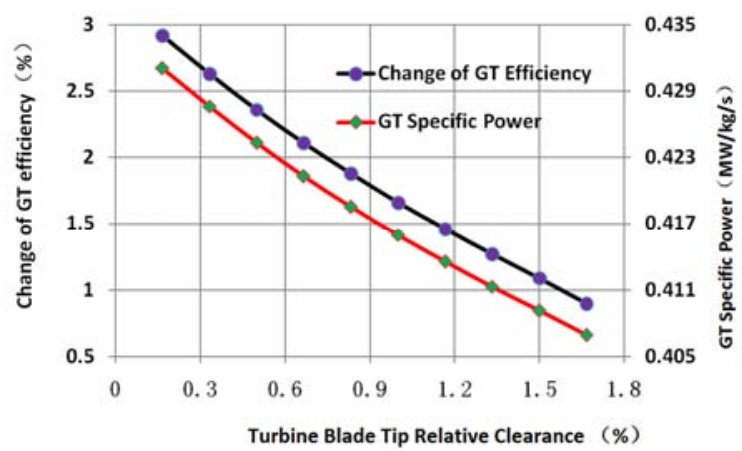

(a) 


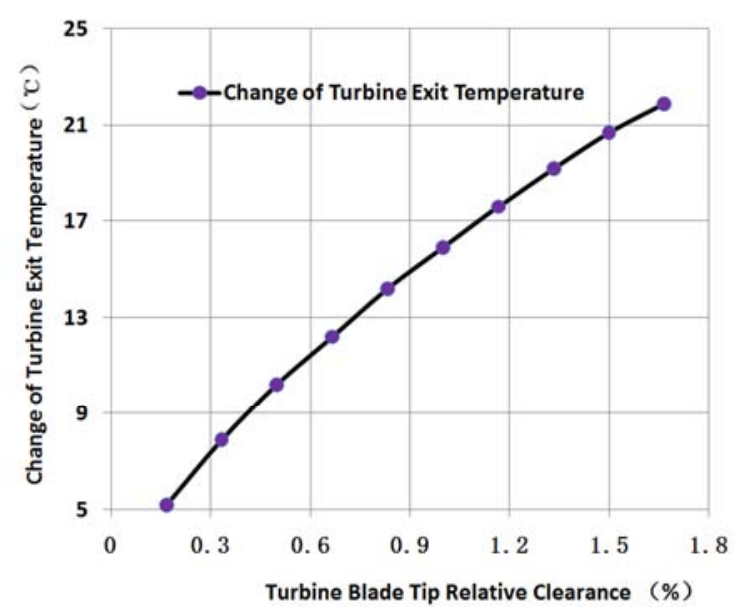

(b)

Figure 15. The effect of Turbine Blade Tip Clearance.

Turbine blade tip relative clearance varies in the ranges of $0-1.8 \%$ in this study. The resulting trends of GT efficiency, GT specific power and turbine exit temperature with the variation of turbine blade tip relative clearance are presented in Figure 15. Figure 15(a) shows that both GT efficiency and GT specific power nearly have a linear decrease with the increasing of turbine blade tip clearance. When turbine blade tip clearance increases $0.17 \%$, the GT efficiency decreases about $0.2 \%$, while the GT specific power decreases about $0.003 \mathrm{MW} / \mathrm{kg} / \mathrm{s}$. Figure 15 (b) shows turbine exit temperature nearly has a linear increase with the increasing of turbine blade tip clearance, turbine exit temperature decreases about $2^{\circ} \mathrm{C}$ when turbine blade tip clearance increases $0.17 \%$. That's because blade clearance loss has a dominated effect on the blade loss comprared to the profile loss, trailing edge loss, secondary loss and cooling loss.

The clearance of compressor also have a big impact on the efficiency for both compressor and GT, and also for the surge of compressor, however it will not be discussed in this paper. The tip clearance is determined by the design technology, and the clearance control technology is wildly used in MHI, GE, SIEMENS and ALSTOM's J-class and H-class GTs. Besides the design technology, the manufacturing accuracy is also very important for the control of tip clearance.

\subsection{TurbineBlade Metal Temperature}

Turbine nozzle and rotor blade allowable metal temperatures both varies in the ranges of $700-1150^{\circ} \mathrm{C}$ in this study, which are thought possible ranges for industry GT. The resulting trends of GT efficiency, GT specific power and turbine exit temperature with the variation of turbine nozzle and rotor blade allowable metal temperatures are presented in Figure 16 and Figure 17. Figure 16(a) and Figure 17(a) show that both GT efficiency and GT specific power increase with the increasing of turbine nozzle and rotor blade allowable metal temperature.

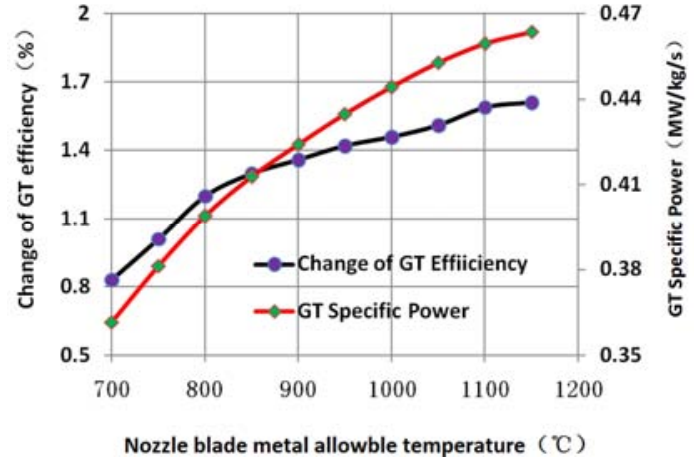

(a)

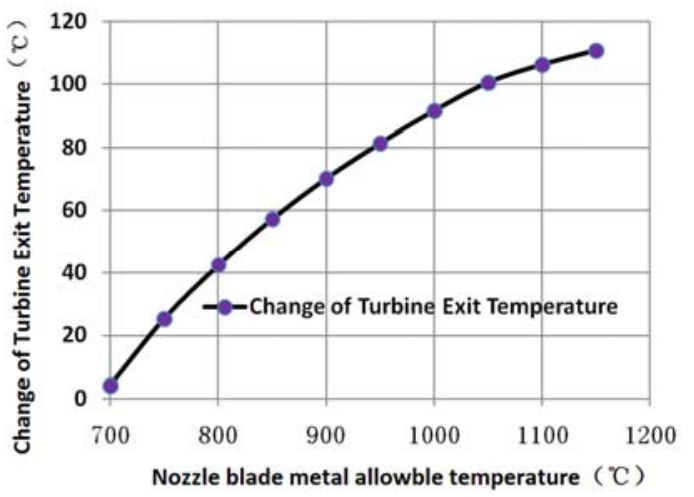

(b)

Figure 16. The effect of Turbine Nozzle Blade Metal Temperature.

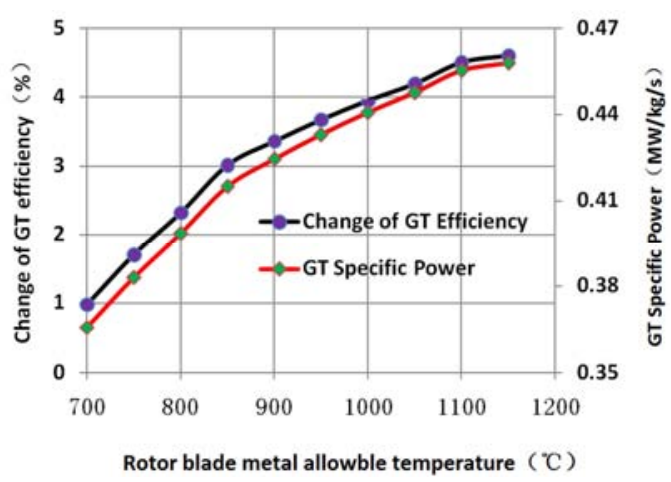

(a)

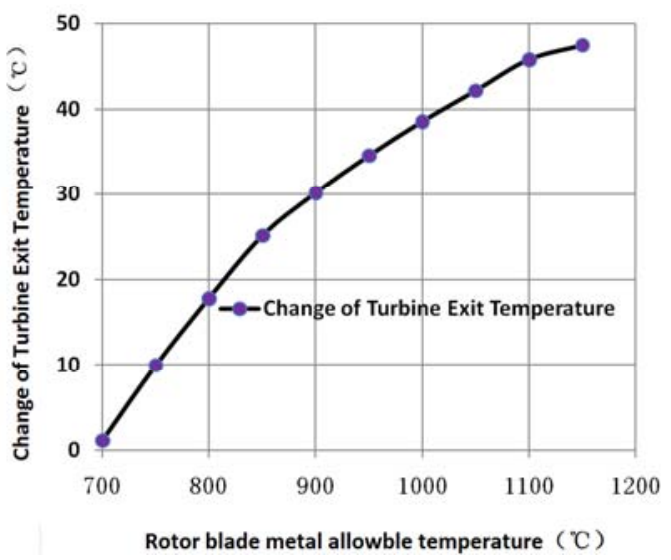

(b)

Figure 17. The effect of Turbine Rotor Blade Metal Temperature. 
When turbine nozzle blade allowable metal temperature increases from $700^{\circ} \mathrm{C}$ to $800^{\circ} \mathrm{C}$, the GT efficiency has a significant increasing, about $0.37 \%$, GT efficiency increases about $0.1 \%$ in every $100^{\circ} \mathrm{C}$ when nozzle blade allowable metal temperature increases from $800^{\circ} \mathrm{C}$ to $1150^{\circ} \mathrm{C}$. For rotor blade, the inflection point is $850^{\circ} \mathrm{C}$, GT efficiency increases about $0.7 \%$ in every $50^{\circ} \mathrm{C}$ when turbine rotor blade allowable metal temperature is between $700^{\circ} \mathrm{C}$ to $850^{\circ} \mathrm{C}$; GT efficiency increases about $0.3 \%$ in every $50^{\circ} \mathrm{C}$ when rotor blade allowable metal temperature is between $850^{\circ} \mathrm{C}$ to $1100^{\circ} \mathrm{C}$; GT efficiency increases about $0.1 \%$ when the temperature increases from $1100^{\circ} \mathrm{C}$ to $1150^{\circ} \mathrm{C}$. GT specific power increases from 0.361 $\mathrm{MW} / \mathrm{kg} / \mathrm{s}$ to $0.464 \mathrm{MW} / \mathrm{kg} / \mathrm{s}$ and from $0.366 \mathrm{MW} / \mathrm{kg} / \mathrm{s}$ to 0.458 $\mathrm{MW} / \mathrm{kg} / \mathrm{s}$ when the nozzle and rotor blade allowable metal temperature inreases from $700^{\circ} \mathrm{C}$ to $1150^{\circ} \mathrm{C}$ respectively.

Figure 16(b) and Figure 17(b) show that the turbine exit temperature increases with the increasing of turbine nozzle and rotor blade allowable metal temperature. Turbine exit temperature increases $107^{\circ} \mathrm{C}$ and $46.3^{\circ} \mathrm{C}$ when the nozzle and rotor blade allowable metal temperature increases from $700^{\circ} \mathrm{C}$ to $1150^{\circ} \mathrm{C}$ respectively.

That's because the required cooling air flow will be significantly reduced with the blade metal allowable temperature increasing. So, the loss will be reduced, more high-pressure high-temperature gas involved to work, and the efficiency and specific power will be increased. Blade metal allowable temperature can be increased by using of advanced turbine blade material and TBC coating, almost all the GT companies make their best to get advanced turbine blade material and low thermal conductivity TBC coating to reduce the cooling air for higher GT efficiency.

\subsection{Turbine Exit Diffuser Cp}

Turbine exit diffuser $\mathrm{Cp}$ varies from 0.3 to 0.9 in the calculation. The resulting trends of GT efficiency, GT specific power and turbine exit temperature with the variation of turbine exit diffuser $\mathrm{Cp}$ are presented in Figure 18. Figure 18(a) shows that both GT efficiency and GT specific power nearly have a linear increasing with the increasing of $\mathrm{Cp}$. When turbine exit diffuser $\mathrm{Cp}$ increases 0.1 , the GT efficiency increases about $0.25 \%$, while the GT specific power increases about $0.003 \mathrm{MW} / \mathrm{kg} / \mathrm{s}$. Figure 18(b) shows turbine exit temperature has a linear decrease with the increasing of $\mathrm{Cp}$, when turbine exit diffuser $\mathrm{Cp}$ increases 0.1 , turbine exit temperature decreases about $2^{\circ} \mathrm{C}$.

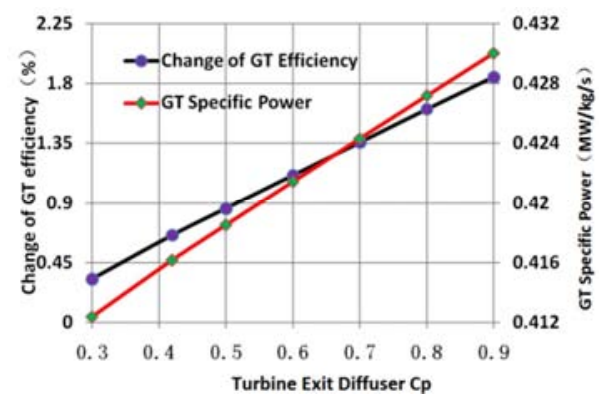

(a)

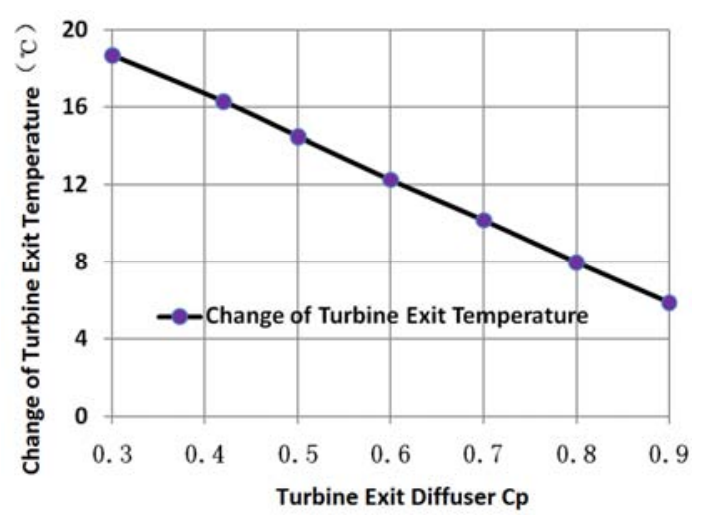

(b)

Figure 18. The effect of Turbine Exit Diffuser Cp.

\section{Conclusions}

Parameters which affect the GT efficiency, GT specific power and turbine exit temperature have been researched, and the key parameters are generalized as below:

(1) When the compressor pressure ratio increases from 5 to 35 , the GT efficiency increases by $16.7 \%$.

GT specific power has an optimum pressure ratio between 18 to 19 at the given assumptions, when the compressor pressure ratio below this optimum number, the GT specific power increases from $0.29 \mathrm{MW} / \mathrm{kg} / \mathrm{s}$ to $0.42 \mathrm{MW} / \mathrm{kg} / \mathrm{s}$ when the compressor pressure ratio increases from 5 to 18 , and decreases from $0.42 \mathrm{MW} / \mathrm{kg} / \mathrm{s}$ to $0.4 \mathrm{MW} / \mathrm{kg} / \mathrm{s}$ when the compressor pressure ratio increases from 18 to 35 .

Turbine exit temperature decreases with the increasing of compressor ratio, when the compressor pressure ratio increases from 5 to 35 , turbine exit temperature decreases by $270^{\circ} \mathrm{C}$.

(2) When compressor efficiency increases $1 \%$, the GT efficiency increases about $0.3 \%$, while the GT specific power increases about $0.01 \mathrm{MW} / \mathrm{kg} / \mathrm{s}$. Turbine exit temperature is nearly kept the same when the compressor efficiency varies.

(3) When compressor exit diffuser Cp increases 0.1, the GT efficiency increases about $0.1 \%$, while the GT specific power increases about $0.001 \mathrm{MW} / \mathrm{kg} / \mathrm{s}$. When compressor exit diffuser $\mathrm{Cp}$ increases 0.1, turbine exit temperature decreases about $0.6^{\circ} \mathrm{C}$.

(4) When combustor pressure loss increases $1 \%$, the GT efficiency decreases about $0.2 \%$, while the GT specific power decreases about $0.002 \mathrm{MW} / \mathrm{kg} / \mathrm{s}$. When the loss increases $1 \%$, turbine exit temperature decreases about $1.3^{\circ} \mathrm{C}$.

(5) When the turbine inlet temperature increases from $1300 \mathrm{~K}$ to $2000 \mathrm{~K}$, the GT efficiency has a significant increasing till $1400 \mathrm{~K}$, then GT efficiency is decreased, GT has a best efficiency when the turbine inlet temperature is $1400 \mathrm{~K}$ in this calculation; GT specific power inceases with the inceasing of turbine inlet temperature, GT specific power increases from $0.27 \mathrm{MW} / \mathrm{kg} / \mathrm{s}$ to $0.47 \mathrm{MW} / \mathrm{kg} / \mathrm{s}$ when the turbine inlet temperature inreases from $1300 \mathrm{~K}$ to $2000 \mathrm{~K}$.

Turbine exit temperature increases $259^{\circ} \mathrm{C}$ when the turbine inlet temperature increases from $1300 \mathrm{~K}$ to $2000 \mathrm{~K}$. 
(6) When OTDF increases 0.05 , the GT efficiency decreases about $0.02 \%$, while the GT specific power decreases about $0.002 \mathrm{MW} / \mathrm{kg} / \mathrm{s}$; When RTDF increases 0.05 , the GT efficiency decreases about $0.15 \%$, while the GT specific power decreases about $0.004 \mathrm{MW} / \mathrm{kg} / \mathrm{s}$. Turbine exit temperature has a linear decreasing with the increasing of OTDF and RTDF, when OTDF increases 0.05, turbine exit temperature decreases about $5^{\circ} \mathrm{C}$; turbine exit temperature decreases about $2.3^{\circ} \mathrm{C}$ while RTDF increases 0.05 .

(7) When turbine efficiency increases $1 \%$, the GT efficiency increases about $0.6 \%$, while the GT specific power increasse about $0.007 \mathrm{MW} / \mathrm{kg} / \mathrm{s}$. Turbine exit temperature nearly has a linear decrease with the increasing of turbine efficiency, turbine exit temperature decreasse about $5^{\circ} \mathrm{C}$ when turbine efficiency increases $1 \%$.

(8) When turbine blade tip clearance increases $0.17 \%$, the GT efficiency decreases about $0.2 \%$, while the GT specific power increases about $0.003 \mathrm{MW} / \mathrm{kg} / \mathrm{s}$. Turbine exit temperature decreases about $2^{\circ} \mathrm{C}$ when turbine blade tip clearance increases $0.17 \%$.

(9) When turbine nozzle blade allowable metal temperature increases from $700^{\circ} \mathrm{C}$ to $800^{\circ} \mathrm{C}$, GT efficiency has a significant increasing, about $0.37 \%$, GT efficiency increases about $0.1 \%$ in every $100^{\circ} \mathrm{C}$ when nozzle blade allowable metal temperature increases from $800^{\circ} \mathrm{C}$ to $1150^{\circ} \mathrm{C}$. For rotor blade, the inflection point is $850^{\circ} \mathrm{C}$, GT efficiency increases about $0.7 \%$ in every $50^{\circ} \mathrm{C}$ when turbine rotor blade allowable metal temperature is between $700^{\circ} \mathrm{C}$ to $850^{\circ} \mathrm{C}$; GT efficiency increases about $0.3 \%$ in every $50^{\circ} \mathrm{C}$ when rotor blade allowable metal temperature is between $850^{\circ} \mathrm{C}$ to $1100^{\circ} \mathrm{C}$; GT efficiency increases about $0.1 \%$ when the temperature increases from $1100^{\circ} \mathrm{C}$ to $1150^{\circ} \mathrm{C}$. GT specific power increases from $0.361 \mathrm{MW} / \mathrm{kg} / \mathrm{s}$ to $0.464 \mathrm{MW} / \mathrm{kg} / \mathrm{s}$ and from $0.366 \mathrm{MW} / \mathrm{kg} / \mathrm{s}$ to $0.458 \mathrm{MW} / \mathrm{kg} / \mathrm{s}$ when the nozzle and rotor blade allowable metal temperature inreases from $700^{\circ} \mathrm{C}$ to $1150^{\circ} \mathrm{C}$ respectively. Turbine exit temperature increases $107^{\circ} \mathrm{C}$ and $46.3^{\circ} \mathrm{C}$ when the nozzle and rotor blade allowable metal temperature inreases from $700^{\circ} \mathrm{C}$ to $1150^{\circ} \mathrm{C}$ respectively.

(10) When turbine exit diffuser Cp increases 0.1, the GT efficiency increases about $0.25 \%$, while the GT specific power increases about $0.003 \mathrm{MW} / \mathrm{kg} / \mathrm{s}$. Turbine exit diffuser $\mathrm{Cp}$ increases 0.1 , turbine exit temperature decreases about $2^{\circ} \mathrm{C}$.

\section{Nomenclature}

$\mathrm{GT}$
$\mathrm{P}$
$\mathrm{T}$
$\gamma$
$\mathrm{Ma}$
$\eta_{\text {int } a k e}$
$\eta_{c}$
$\mathrm{Q}$
$\eta_{\mathrm{b}}$
$m_{f}$
$m_{i}$

Gas Turbine

Pressure

Temperature

Isentropic Exponent

Mach Number

Adiabatic intake efficiency

Adiabatic compressor efficiency

Fuel LCV

Combustion efficiency

Mass flow of fuel

Mass flow of air

$\begin{array}{ll}\text { FAR } & \text { Fuel-air ratio } \\ \rho & \text { Density } \\ u_{e} & \text { Exit speed of the exhaust section } \\ \text { TBC } & \text { Tturbine barrier coating } \\ \text { Cp } & \text { Static pressure recovery factor } \\ \text { OTDF } & \text { Radial temperature distribution factor } \\ \text { RTDF } & \text { Radial temperature distribution factor } \\ \text { GT specific power } & \text { GT power/mass flow } \\ \text { Subscripts } & \\ \text { a } & \text { Entrance of intake section } \\ 2 & \text { Entrance of compressor } \\ \mathrm{s} & \text { Isoentropic process in the ideal state } \\ 0 & \text { Stagnation value } \\ 3 & \text { Exit of compressor } \\ 4 & \text { Inlet of turbine } \\ 5 & \text { Exit of turbine } \\ 7 & \text { Exit of exhaust section }\end{array}$

\section{Appendix}

The nozzle coolant is remixed upstream of the calculation point and the rotor coolant is remixed downstream of the exit calculation point. The nozzle coolant does work within the local stage. All of the disk packing flow is assumed to remix downstream of the rotor. Rotor coolant is assumed to do no work within the local stage although the work required to pump it through the blades is accounted for a penalty to the power. The remix flow enthalpy changes resulting from disk windage and pumping, along with the casing heat loss, are accounted for the downstream of the exit calculation point. The heat loss caused by the heat transfer between the vanes/blades and the surrounding and the mixing effect of the cooling air and the mainstream flow is based on the Barry's paper, while the aerodynamic efficiency is calculated by the Kacker\&Okapuu's loss model[20,21].

The coolant fraction is calculated for each blade row where the inlet temperature is higher than the allowable metal temperature. The blade row inlet temperature incorporate the OTDF and RTDF for the nozzle and rotor respectively. The coolant fraction can be got from figure 19.

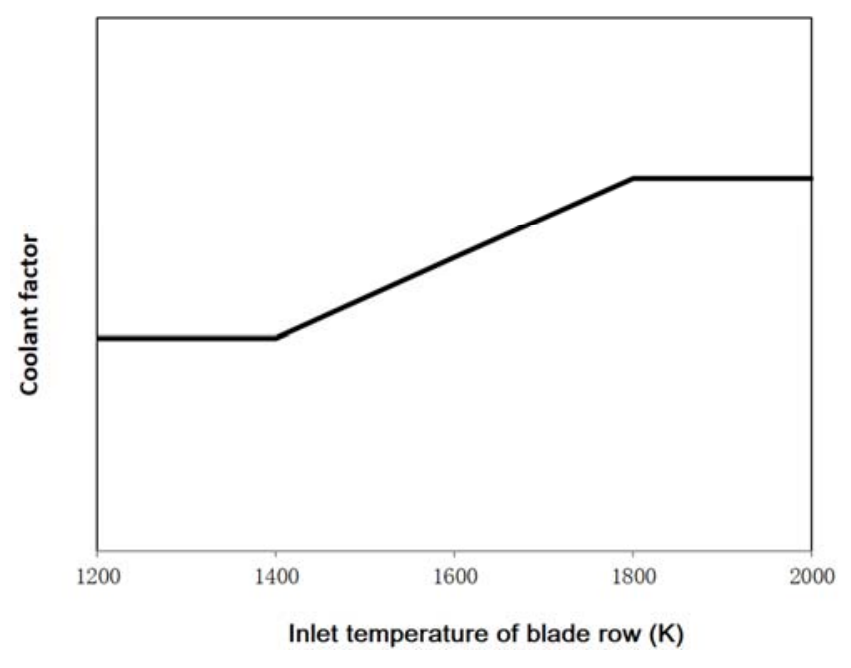

Figure 19. Coolant factor variation with inlet temperature of blade row. 


\section{References}

[1] UshiyamaI. Theoretically estimating the performance of gas turbines under varying atmospheric conditions [J], Journal of Engineering for Power, 1976, 98: 68-79.

[2] Hadik A AEl. The Impact of atmospheric conditions on gas turbine performance $[\mathrm{J}]$, Journal of Engineering for Gas Turbines and Power, 1990, 112 (4): 590.

[3] Baugh J W, Mckillop A A, Trelevan K. An analysis of the performance of a gas turbine cogeneration plant [J], Journal of Engineering for Gas Turbines and Power, 1983, 105 (4): 816-820.

[4] KhaliqA, ChoudharyK. Thermodynamic performance assessment of an indirect intercooled reheat regenerative gas turbine cycle with inlet air cooling and evaporative aftercooling of the compressor discharge [J], International Journal of Energy Research, 2010, 30 (15): 1295-1312.

[5] Cai R X. The basic performance of combined cycles and their optimum gas turbine pressure ratios [C], ASME Paper, 1995, 95-GT-416.

[6] Yoshida T, Morikawa T, GotouJ, Hayashi Y. Gas turbine performance analysis method and gas turbine performance analysis system [P], US7797113B2, 2010-09-14.

[7] Sanjay, Singh O, Prasad B N. Comparative performance analysis of cogeneration gas turbine cycle for different blade cooling means $[\mathrm{J}]$, International Journal of Thermal Sciences, 2009, 48: 1432-1440.

[8] Sanjay, Investigation of effect of variation of cycle parameters on thermodynamic performance of gas-steam combined cycle [J], Energy, 2011, 36: 157-167.

[9] Kumar S, Singh O. Performance evaluation of simple aero gas turbine cycle with transpiration cooling of gas turbine blades [J], International Journal of Emerging Technology and Advanced Engineering, 2013, 3 (3): 416-420.

[10] Shukla A K, Singh O. Performance evaluation of steam injected gas turbine based power plant with inlet evaporative cooling, Applied Thermal Engineering, 2016, 102: 454-464.

[11] Elwekeel F N M, Abdala A M M. Effect of mist cooling technique on exergy and energy analysis of steam injected gas turbine cycle [J], Applied Thermal Engineering, 2016, 98: 298-309.

[12] Singh H, Tayal P K, Goyal N, Rastogi P M. Effect of ambient temperature, gas turbine inlet temperature and compressor pressure ratio on performance of combined cycle power plant [J], International Journal of Advanced Technology in Engineering and Science, 2016, 4 (1): 1-13.

[13] Gas Turbine Performance. P. P. Walsh\& P Fletcher, Blackwell Science 1998 ISBN 0-632-04874-3

[14] Takao Sugimoto, Katsushi Nagai et al. Developoment of a 20MW-Class high-efficiency Gas Turbine L20A [C], ASME Paper, 2002, 2002-GT-30255.

[15] E. Akita et al. 'M501F/M701F Gas Turbine Uprating', ASME TURBO EXPO 2001.

[16] EnnioMacchi, GiovanniLozza et al. 'Gas/Steam Combined Cycles Fueled by Various Energy Sources for Large-Scale Power Production', 2015

[17] MHI J-Series Gas Turbine Development, 2012.

[18] 9HA POWER PLANTS.

[19] Hitachi, Ltd, Smart AHAT System Smart Energy Solutions by Advanced Humid Air Turbine, 2013.

[20] Barry, B, VKI Lecture Series 83, 1976.

[21] Kacker, S. C, Okapuu, U. 'A mean line prediction method for axial flow turbine efficiency' ASME 81-GT-58 1981. 